Drug Deliv Transl Res. 2011 December 1; 1(6): 409-419. doi:10.1007/s13346-011-0046-y.

\title{
Advances in Stroke Therapy
}

\author{
Hayder Jaffer, Viola B. Morris, Desiree Stewart, and Vinod Labhasetwar \\ Department of Biomedical Engineering, Lerner Research Institute, Cleveland Clinic, Cleveland, \\ $\mathrm{OH} 44195$
}

\begin{abstract}
Stroke is a leading cause of death, long-term disability, and socioeconomic costs, highlighting the urgent need for more effective treatments. Intravenous administration of tissue plasminogen activator (t-PA) is the only FDA-approved therapy to re-establish cerebral blood flow. However, because of increased risk of hemorrhage beyond $3 \mathrm{~h}$ post stroke, few stroke patients (1-2\%) benefit from t-PA; t-PA, which has neurotoxic effects, can also aggravate the extent of reperfusion injury by increasing blood-brain barrier permeability. An alternative strategy is needed to extend the window of intervention, minimize damage from reperfusion injury, and promote brain repair leading to neurological recovery. Reactive oxygen species (ROS), generated soon after ischemia and during reperfusion and thereafter, are considered the main mediators of ischemic injury. Antioxidant enzymes such as catalase, superoxide dismutase, etc. can neutralize ROS-mediated injury but their effective delivery to the brain remains a challenge. In this article, we review various therapeutic approaches including surgical interventions, and discuss the potential of nanoparticle-mediated delivery of antioxidants for stroke therapy.
\end{abstract}

\section{Keywords}

Brain Ischemia; Reactive Oxygen Species; Nanoparticles; Antioxidant Enzymes; Oxidative Stress; Neuronal Damage; Blood-Brain Barrier

\section{Introduction}

Stroke is a sudden loss of brain function resulting from interference with the blood supply to the central nervous system (CNS). Normal cerebral blood flow (CBF) is approximately 50$60 \mathrm{ml} / 100 \mathrm{~g} / \mathrm{min}$. The reduction in CBF below $20 \mathrm{ml} / 100 \mathrm{~g} / \mathrm{min}$ results in an electrical silence and less than $10 \mathrm{ml} / 100 \mathrm{~g} / \mathrm{min}$ causes irreversible neuronal injury [1, 2]. Lack of blood circulation to the brain deprives neurons of necessary glucose and oxygen. Neurons are the impulse transmitters; hence they require constant supply of energy. Up to $85 \%$ of all strokes are of ischemic origin, with most attributable to blockage of one or more cerebral arteries by blood clots, with resulting reduction in cerebral perfusion. The remaining stroke cases are hemorrhagic, involving either intracerebral or subarachnoid hemorrhage.

\section{Acute, subacute and chronic events following stroke}

Cerebral ischemia results in a number of hemodynamic, biochemical, and neurophysiologic alterations [3]. A series of complex acute, subacute and chronic events occur after the incidence of stroke and reperfusion [4]. Ischemic injury involves energy failure, loss of cell ion homeostasis, acidosis, increased intracellular calcium excitotoxicity, free radical-

\footnotetext{
*Author for correspondence: Vinod Labhasetwar, Ph.D., Department of Biomedical Engineering/ND20, Cleveland Clinic, 9500 Euclid Avenue, Cleveland, OH 44195, Tel: 216/445-9364, Fax 216/444-9198, labhasv@ ccf.org.
} 
mediated toxicity, and pathological permeability of the blood-brain barrier (BBB). Free radicals, specifically reactive oxygen species (ROS) that are generated soon after ischemia, as well as in later stages of ischemic reperfusion (e.g., by inflammatory cells), are the fundamental mediators of reperfusion injury.

\section{Mechanisms of neuronal injury}

The development of hypoxic-ischemic neuronal injury is significantly influenced by the release of excitatory neurotransmitters, primarily glutamate and aspartate in the brain. This process is called excitotoxicity and is activated by depletion of cellular energy stores. Glutamate, normally stored inside the synaptic terminals, is released in the extracellular space in a depleted energy state, which then results in the opening of calcium channels associated with N-methyl- D asapartate (NMDA) and alpha-amino-3-hydroxy-5-methyl-4isoxanole propionate (AMPA) receptors. This leads to influx of calcium, sodium and chloride ions and efflux of potassium ions. [5-7]. The influx of calcium is responsible for the activation of a series of destructive enzymes such as proteases, endonucleases, and lipases that allow release of cytokines and other inflammatory mediators, resulting in the loss of cellular integrity $[8,9]$. Inflammatory mechanisms play an important role in tissue injury by inducing the rapid production of many different inflammatory mediators. Within 30 minutes after ischemia and reperfusion, leukocytes recruited to the ischemic area activate mediators of inflammation such as oxygen free radicals, cytokines, and nitric acid.

\section{Role of free radicals in cerebral damage}

A vast amount of data implicates oxygen-derived free radicals (especially superoxide and hydroxyl radicals) and high-energy oxidants (such as peroxynitrile) as mediators of inflammation in ischemia/reperfusion injury [10]. Free radicals are highly reactive molecules generated predominantly during cellular respiration and normal metabolism. Imbalance between cellular production of free radicals and the ability of cells to defend against them is referred to as oxidative stress [11]. After brain injury by ischemic stroke, the production of ROS dramatically increases, leading to tissue damage via several different cellular, molecular pathways, and mechanical pressure (Figure 1). ROS can cause damage to cellular components such as lipids, protein, and nucleic acids, leading to subsequent cell death [12]. Damage can become more widespread due to weakened cellular antioxidant defense systems in ischemia. ROS are the major stimulators of inflammatory cytokine production (such as interleukin-1, tumor necrosis factor- $\alpha$, and interferon- $\gamma$ ) and protease secretion by microglia, leukocytes, and resident cells of the neurovascular unit [13]. As these neuroinflammatory mechanisms become activated, alterations in cytokine profiles, adhesion-molecule expression, and tight-junction components mediate further vascular leakage. Significant evidence exists suggesting that ROS are involved in every fundamental physiological step that leads to neuronal death [14] and thus are considered an important target in developing an effective stroke therapy [15].

\section{Therapeutic strategies and potential issues}

In treating acute ischemic stroke, two primary strategies are followed: 1) limiting the ischemic insult by early reperfusion and 2) interfering with the pathobiochemical cascade leading to ischemic neuronal damage. In developing an effective therapy, one must also weigh the deleterious consequences of reperfusion injury versus the effects of delay in resuming blood supply to the brain [16]. Within an hour of ischemia, two layers of cerebrovascular tissue develop: the inner core displaying necrosis of both neuronal as well as supporting glial elements, and the outer layer of less severe ischemia called the ischemic penumbra. The cells within the ischemic penumbra can be recovered if timely therapeutic intervention is administered. The size of the ischemic penumbra (portion of the brain that 
can be rescued) diminishes with time, as the infarct core progressively becomes hypoperfused tissue that cannot be rescued following reperfusion. Ischemic damage in the penumbra, however, is reversible and is the target of rescue via re-establishing blood flow [17].

\section{Reperfusion Therapies}

\section{Thrombolytic Agents}

The critical time period during which this volume of brain tissue is at risk is referred to as the "window of opportunity". At present, intravenous administration of tissue plasminogen activator (t-PA) within $3 \mathrm{~h}$ of symptom onset is the only US FDA-approved treatment available to re-establish cerebral blood flow. Early reperfusion with t-PA increases recovery from stroke symptoms by $\sim 30 \%$, with a low rate of serious complications. This will not only rescue neuronal and glial cells within the penumbra, but also glial cells from the central ischemic core zone, thereby limiting the size of infarcted tissue [18]. However, despite the beneficial outcome of early reperfusion, only $3 \%-8.5 \%$ of eligible stroke patients receive tPA because of the possibility of intracranial hemorrhage [19]. The American Heart Association recently suggested that selected patients may benefit from t-PA up to $4.5 \mathrm{~h}$ after stroke, but some counter that the risk of hemorrhagic complications beyond $3 \mathrm{~h}$ following ischemia is significantly greater due to breakdown of the BBB [20]. In addition, the increase in cerebrovascular permeability results in diffusion of t-PA to the brain parenchyma [21], causing neurotoxicity [22].

To extend treatment availability to patients with stroke and to reduce the potential for intracranial hemorrhage, intraarterial thrombolysis is a viable option for those who present for medical treatment in the 3-6 hour time window [23]. The strategy behind intraarterial administration is rapid local delivery of a thrombolytic agent through a microcatheter placed near the site of occlusion. This leads to improved recanalization and reduced hemorrhagic complications due to lower doses of thrombolytic agent required to resume blood flow [24]. The disadvantages include the relative complexity of the procedure, delays in initiation of treatment, required technical expertise, and the invasiveness of the procedure [25]. To address the above issues, particularly to compensate for the delay in receiving the treatment, a combination therapy of intravenous and intraarterial thrombolysis has been tested. The initial partial recanalization with intravenous injection of t-PA is followed by complete recanalization via direct intraarterial delivery [26].

\section{Mechanical thrombectomy}

When thrombolysis is ineffective or is not considered as a viable option, mechanical devices are used to recanalize the occluded cerebral vessel to restore the flow [27]. One such device, the Merci Retriever ${ }^{\mathrm{TM}}$ (Concentric Medical, Mountain View, CA), consists of a flexible corkscrew-shaped tapered nitinol wire with 5 helical loops that can be threaded in the thrombus, which is then removed by traction [28]. The first prospective study that examined a device-based treatment option for ischemic stroke showed a $43 \%$ recanalization rate with the device alone and a 64\% recanalization rate with additional intraarterial administration of t-PA [29]. The Catch System ${ }^{\text {TM }}$ (BALT Extrusion, Montmorency, France) is a tiny wire basket that retrieves the thrombus [30]. Another useful new technique has been developed in which the clot is simultaneously aspirated from the vessel as it is being extracted. The Phenox Clot Retriever ${ }^{\mathrm{TM}}$ (Phenox, Bochum, Germany) consists of a highly flexible core wire compound resembling a pipe cleaner with perpendicularly oriented polyamide microfilaments that create an attenuated palisade. It is deployed distal to the clot and is slowly pulled back under continuous aspiration via the guiding catheter. 
The BONnet $^{\mathrm{TM}}$ (Phenox, Bochum, Germany) consists of a self-expanding nitinol braiding with polyamide filaments passing through the interior to enlarge the surface area and enable better fixation of the thrombus mass [31]. The Penumbra System ${ }^{\mathrm{TM}}$ (Penumbra, Alameda, CA) has been FDA-approved as a dual approach to clot extraction using aspiration and debulking of the thrombus to reduce or eliminate the clot burden $[32,33]$. The system includes reperfusion microcatheters that are connected to an aspiration pump through an aspiration tube. A separator is advanced and retracted within the lumen of the reperfusion catheter to debulk the clot, followed by clot retrieval with a ring device that engages the thrombus by capturing it in clasps with a cylinder that is then withdrawn. The recanalization rate is more then $80 \%$ and the device has an excellent safety profile $(<3 \%$ procedural serious adverse events) [34]. This system has the potential of reopening a vessel without the use of thrombolytics, thus offering dual options for recanalization via a single access platform, and decreases the need to blindly penetrate into the occluded vascular segment because it operates from the proximal end of the clot [35].

Percutaneous transluminal angioplasty (PTA) is particularly useful in cases of atherothrombotic disease, in which the residual stenosis may reduce flow sufficiently to lead to rethrombosis [36]. PTA can be used alone or with subsequent thrombolytic therapy for distal embolization. The largest study of angioplasty for acute stroke showed that recanalization was achieved in $63.9 \%$ of thrombolytic-only treated patients, versus $91.2 \%$ in the combined thrombolytic plus PTA treatment group. Because of the risk of vessel rupture and distal embolization, this technique is generally reserved for patients whose flow cannot be restored by more conservative methods [36]. Interventional treatment of acute ischemic stroke with self-expanding stents for flow restoration has been shown to be an effective method for achieving re-canalization. In a prospective study, Stent- Assisted Recanalization in Acute Ischemic Stroke, 100\% successful recanalization was demonstrated in 20 patients, with only 1 symptomatic hemorrhage. The disadvantage of this approach is the implantation of a permanent prosthesis and the need for continuous antiplatelet therapy [37, 38].

\section{Surgical interventions}

Surgical reconstruction of the cervical carotid artery may be indicated in patients with transient ischemic attack but who are otherwise in good neurologic condition. Another option, microsurgical embolectomy of intracranial vessels, is an invasive procedure involving craniotomy, opening the occluded artery to remove the clot, and reperfusion of the affected area. However, because the procedure is performed through the subarachnoid space via a small craniotomy with a minimal skin incision, it is relatively safe. This can be a last therapeutic option for those patients who are ineligible to receive intravenous or intraarterial thrombolysis, or in the case of failed mechanical thrombectomy. Again, there is a restrictive time window of less than 6 hours from stroke onset for the intervention to be effective. Another surgical procedure utilized in ischemic stroke patients is brain decompression. In the case of major vessel occlusion, large cerebral infarcts is developed, commonly associated with rapidly progressing malignant cerebral edema [39]. This leads to compromised neuronal metabolism, decreased cerebral perfusion, and impaired oxygenation. In addition, shifting of intracranial contents and transtentorial herniation, is the leading cause of death in these patients [40]. Because this kind of cerebral edema is refractory, i.e., not amenable to other forms of treatment, brain decompression is considered a therapy of last resort. Decompressive hemicraniectomy with duraplasty is a complex procedure in which a part of the skull vault is removed and the dura is opened to give more room for the expanding brain. Then, a Silastic sheet, watertight Lyodura, or pericranial grafts are placed over the craniectomy for brain protection. This procedure has been shown to result in increased cerebral perfusion, better survival, improved neurological outcomes, and a reduction in the volume of the infarction [41, 42]. Another, more invasive craniotomy 
involves resection of infarcted tissue and/or uncal resection. Resection of dead tissue makes room for reperfusion of live tissue in the affected area. Both types of procedures appear to yield satisfactory outcome results.

\section{Neuroprotective Therapies}

Thrombolysis is likely an effective therapeutic modality because it helps restore blood flow and improve cellular metabolism in ischemic regions not yet irreversibly injured. However, thrombolysis is not targeted at the cellular consequences of ischemia. Therefore, it is essential to add a component that would act as a neuroprotective or prevent the damage caused by reperfusion injury. In fact, the Stroke Progress Review Group, which is charged with assisting the National Institute of Neurological Disorders and Stroke (NINDS) in addressing the Institute's Stroke Research Program, has recommended research on combinations of neuroprotectants or neuroprotectants plus reperfusion therapy. Addition of neuroprotectants would protect neurons, which are susceptible to apoptosis, and could minimize the damage due to reperfusion injury.

\section{Antioxidant therapy}

Upon reperfusion, cells are often in a state of oxidative stress, which results in further tissue injury, known as reperfusion injury [43, 44]. ROS are usually scavenged by antioxidant enzymes, primarily superoxide dismutase (SOD), by catalyzing the dismutation reaction of the superoxide anion to hydrogen peroxide $\left(\mathrm{H}_{2} \mathrm{O}_{2}\right)$. Catalase and glutathione peroxidase, on the other hand, protect cells from the toxic effects of $\mathrm{H}_{2} \mathrm{O}_{2}$ by catalyzing its decomposition into water [45]. However, two pharmacodynamic factors impede the straightforward use of native forms of antioxidant enzymes in cerebral ischemia. First, their molecular weight is well below the renal glomerular filtration cutoff, resulting in their rapid clearance from systemic circulation (e.g., $\mathrm{t}_{1 / 2}$ of SOD in rats $=4-8 \mathrm{~min}$, catalase $=8-10 \mathrm{~min}$ ). Second, they are negatively charged at physiologic $\mathrm{pH}$ and therefore do not readily cross cell membranes [46]. Transient disruption of BBB permeability might permit some access of exogenous enzymes to ischemic neuronal tissue, but they do not permeate cells; neurons and astrocytes do not appear to take up the native enzyme under normal conditions, and hence cannot neutralize ROS formed intracellularly [47]. Because of these challenges, animal studies have shown no improvement in cerebral blood flow or neurological recovery with SOD or SOD with catalase [48, 49].

Different alternatives have been investigated to address these issues: for instance, PEGylation and lecithinization to improve the circulation half-life [50] and fusion of enzymes, e.g. SOD, with cell membrane-penetrating peptides like transactivator of transcription (TAT) of human immunodeficiency virus or tetanus toxin fragment to increase its ability to cross the BBB [51]. However, there are limitations to these modifications. For example, PEGylated SOD (PEG-SOD) increases the enzyme's stability in circulation from 6 min to $36 \mathrm{~h}$, but it limits the permeability of SOD across cerebral cell membranes and its ability to be taken up by neuronal cells [52]. Similarly, fusion of different cell-penetrating or cell-specific peptides to target proteins requires a crosslinker via a chemical process that could cause denaturation and loss of activity of the target protein [53]. There is also a concern regarding the possible immune-mediated anaphylactic responses to hybrid proteins given to patients [46]. Intravenous delivery of SOD loaded into liposomes has shown partial inhibition of infarct volume, but the instability of liposomes in vivo (half-life $\sim 4.2 \mathrm{~h}$ ) limits the duration of SOD activity and efficacy $[54,55]$. Our approach uses biocompatible, biodegradable nanoparticles (NPs) loaded with superoxide dismutase (SOD-NPs) with the aim to reduce the damaging effect of ROS. These NPs are formulated using poly dl-lactide co-glycolide (PLGA) with antioxidant enzymes encapsulated. The enzyme encapsulated in NPs is released in active form. Our initial studies demonstrated the neuroprotective effect of 
SOD-NPs in oxidative stress-challenged human neural cells, whereas SOD in solution and PEG-SOD were ineffective. The mechanism of protective efficacy of SOD- NPs appears to be due to sustained bioavailability of antioxidants and intracellular delivery of antioxidant enzymes [56]. In our first in vivo ischemic middle cerebral arterial occlusion rat stroke model [57], we determined that the most efficient method of delivery of NPs is via intracarotid artery injection. The study with dye-loaded NPs demonstrated NP localization primarily to the cortex and striatal regions of the ischemic hemisphere, but not to the nonischemic hemisphere. Our results demonstrated that over 75\% of SOD-NP-treated animals showed increased survival and neurological recovery over a time period of 28 days (Figure 2). In addition, a reduction in breakdown of the blood-brain barrier in treatment animals was evidenced by significantly decreased Evans blue leakage in the brain (Figure 3A). These results have driven further research into the neuroprotective effects of SOD-NPs (Figure 3B), as well as investigation into how we can further abrogate the negative effects of ROS production in ischemic stroke. The protective effect of SOD-NPs could be due to the direct antioxidant effect of the active enzyme released from the NPs localized in the brain. It is possible that SOD-NPs prevented the cascade of events or acted at several stages in the pathophysiology of reperfusion injury. Breakdown of the BBB is an early event arising from free-radical damage, especially from superoxide radicals generated in endothelial cells during ischemia and reperfusion [58]. SOD-NPs localized in lining of the cerebral vasculature protected the BBB from free-radical injury, which then could have prevented the leukocyte adhesion that otherwise is a common event following reperfusion as well as prevented edema formation [59]. We are investigating further to understand the mechanism of recovery of animals with time. It is quite possible that the conducive conditions created in the brain as a result of the sustained free-radical scavenging effect of SOD released from NPs localized in the brain [60] could have played a role in facilitating the process of angiogenesis and neurogenesis in the infarcted brain. Recently, we began working on developing a thromboembolic rat stoke model to mimic the clinical scenario [61]. We are now testing how SOD-NPs and catalase-loaded NPs, or combination of these formulations, would perform in the presence of t-PA and whether we can extend the window of t-PA treatment with effective antioxidant delivery.

\section{Other therapeutic strategies for ischemic stroke}

The understanding of various pathogenetic mechanisms of stroke leads to the development of newer therapeutic approaches with different modes of action as well as with a wider therapeutic window. Anti-ischemic agents like glutamate antagonists, anti-inflammatory agents, anti- apoptotic agents, and ion-channel modulators are the currently studied therapeutic interventions for ischemic stroke $[62,63]$

\section{Glutamate antagonism}

Glutamate antagonists are the most studied neuroprotective agents. As mentioned earlier, glutamate is one of the excitatory CNS neurotransmitters and is released excessively during ischemia [64]. Several receptors relevant to neuroprotection, such as NMDA, AMPA, KA, and metabotropic receptors, are activated by glutamate. Since the activation of most of these receptors is associated with calcium influx leading to cell damage, both glutamate receptor antagonism and calcium channel blockers might serve a neuroprotective role. Although glutamate receptor antagonists have shown excellent neuroprotective effects in animal studies, these effects have not been validated in clinical studies. As a result, studies of several NMDA antagonists- Selfotel (CGS19755) [65], Eliprodil [66] and Aptiganel (Cerestat, CNS 1102) [67]- have been halted. Calcium channel blockers such as Nimodipine [68] and Flunarizine also showed no significant benefit versus placebo in clinical trials. Despite these failures and various side effects at both the psychiatric and cardiovascular levels, the possibility of a role for glutamate receptor antagonists in neuroprotection still 
exists. A phase III trial with YM872, an AMPA receptor antagonist, is ongoing, and seeks to determine its potential efficacy in combination with $t$-PA thrombolysis. No clinical trials with metabotropic glutamate receptor antagonists have been conducted. It was recently reported that SP-8203, an NMDA antagonist, has dual effects that protect cells against excitotoxicity and improve memory in brain ischemic injuries [69], suggesting a potential therapeutic role of SP-8203 in cerebral ischemic injuries.

The main cause of failure of many approaches in clinical studies is inadequate dosing and timing of therapeutics, particularly an unrealistic time window derived from animal models that cannot be duplicated in humans [70]. The reasons for the failure of the most promising drug in a clinical study (NXY-059 in the SAINT II trial) are that the drug was not given to most patients within a 4- to 6-h time window as was used in animal studies and its inadequate drug levels in the brain [71]. One phase III trial, the FAST-MAG study, which aims to determine the safety of magnesium sulfate when administered acutely in the first minutes after stroke onset, addresses these issues by arming paramedics with tools to obtain consent and administer the experimental therapy within a hyperacute therapeutic window [72]. A pilot study for this trial found significantly improved modified Rankin scores (mRS) at day 90 for trial patients, and the study design has contributed a novel experimental strategy that could benefit other researchers in translating pre-clinical study results to field applications. Recognizing the benefits of pre-hospital neuroprotective agent administration, the Stroke Treatment Academic Industry Roundtable (STAIR) meeting set recommendations for priorities in stroke research, noting that the hyperacute treatment window could potentiate other interventions and increase the time window for other time-sensitive interventions [73].

\section{Anti-inflammatory agents}

Cerebral ischemia activates an inflammatory reaction within hours of the injury.

Suppression of inflammation using a variety of drugs has been shown to reduce infarct area in animal studies. Commonly used anti-inflammatory agents are aspirin and the lipidlowering statins. A combination of aspirin and extended release dipyridamole was found to be more efficacious than aspirin alone for nonfatal stroke by the second European Stroke Prevention Study (ESPS-2) and the European/Australian Stoke Prevention in Reversible Ischemia Trial (ESPRIT) [74]. In an investigation of the anti-inflammatory and neuroprotective properties of statins, the Stoke Prevention by Aggressive Reduction in Cholesterol Level study showed that treatment with high-dose atovastatin reduces the risk of stroke in patients with first attack of stroke and no known coronary artery disease [75]. In addition to aspirin and statins, two leukocyte adhesion inhibitors, Enlimomab and LeukArrest, were studied in patients with ischemic stroke. Although Enlimomab was shown to reduce the damage in stroke models, patients who received it experienced significantly more negative effects relative to placebo controls [76].

Another neuroprotective approach was explored in the "Intravenous Thrombolysis Plus Hypothermia for Acute Treatment of Ischemic Stroke (ICTuS-L)" study of the effects of induced hypothermia and thrombolysis after acute ischemic stroke. Hypothermia is thought to serve a neuroprotective role in stroke via inhibition of the MIP-3 $\alpha$-CCR6 inflammatory pathway [77]. Although hypothermia has been shown to confer some protection against damage in cardiac arrest and neonatal hypoxic-ischemic encephalopathy patients [78, 79], its effectiveness in acute ischemic stroke has not been definitively demonstrated. Negative consequences, including pneumonia, were seen more frequently in patients who had undergone hypothermia treatment, compared to controls in this study. Disappointingly, there was no significant benefit in $\mathrm{mRS}$ between the two trial groups [80]. 


\section{Ion channel modulators}

As previously discussed, the influx of calcium and sodium and efflux of potassium during the ischemic cascade leads to brain tissue damage [81]. Therefore, ion channel modulators might have a neuroprotective role. Nimodipine, a calcium channel blocker that dilates intracranial blood vessels and improves the regional blood flow in the margins of the brain infarct, did not show any benefit in clinical trials. Similarly, Fosphenytoin, the sodium channel blocker, was shown to decrease the amplitude of sodium-dependent action potentials and to block voltage- dependent calcium entry into synaptosomes. Again, phase III clinical trials were terminated due to the lack of demonstrated benefit. The potassium channel activator Maxipost also failed at phase III clinical trials, even though it was expected to protect neurons by inducing neuronal hyperpolarization and decreasing the release of excitatory amino acids [82].

\section{Anti-Apoptotic agents}

Caspase is a group of cysteine proteases that induce apoptotic cascade when activated. Inhibition of caspase activity has been shown to reduce the size of infarction in rodent stoke models [83, 84]. However, none of the caspase inhibitors has yet been tested in clinical trials. A 2009 study on the efficacy of erythropoietin as a neuroprotectant yielded negative effects and safety concerns after it was shown that not only did erythropoietin not confer a neuroprotective benefit, but erythropoietin in combination with the current standard of care, rt-PA, increased the risk of death, intracerebral hemorrhage, brain edema, and thromboembolic events [85]. Thus, future studies should evaluate the effect of putative therapeutic agents in conjunction with the use of rt-PA where appropriate. These studies demonstrate some of the challenges faced in seeking neuroprotective agents to reduce the initial damage wrought by ischemic stroke.

\section{Neuronal Rescue}

Another critical issue in stroke therapy is how to recover areas of infarcted brain that appear irreversibly damaged due to ischemia. To address this issue, research is now focused on understanding neurogenesis, particularly endogenous repair mechanisms such as the involvement of neuronal progenitor cells and their proliferation and differentiation into neural cells [86]. However, use of a small population of endogenous neuronal progenitor cells and their limited capacity to regenerate under inflammatory conditions may not be enough to achieve significant neurological recovery. Therefore, several growth factors (e.g., epidermal, fibroblast, and vascular endothelial growth factors, erythropoietin) have been tested to increase proliferation and migration of progenitor cells. The major challenge seems to be inducing sufficient proliferation to repair the devastating neuronal damage following ischemia, promoting survival of the newly formed cells in the hostile environment, and more importantly, inducing proper connectivity of the newly formed cells with the existing circuitry [86]. An alternative approach is the transplantation of stem cells, but a number of factors could influence the success of this approach, the main one being the survival of the transplanted cells and the likelihood of their proper differentiation into neuronal cells [87, 88].

\section{Acknowledgments}

The study reported here from the authors' laboratory is funded by grant 1R01NS070896 (to VL) from the National Institute of Neurological Disorders and Stroke of the National Institutes of Health. DS is a predoctoral student in Cleveland Clinic's Molecular Medicine Ph.D. Program, which is funded by the "Med into Grad" initiative of the Howard Hughes Medical Institute [http://www.lerner.ccf.org/molecmed/phd/] 


\section{References}

1. Hakim AM. Ischemic penumbra: the therapeutic window. Neurology. 1998; 51(3 Suppl 3):S44-6. [PubMed: 9744833]

2. Jones TH, Morawetz RB, Crowell RM, Marcoux FW, FitzGibbon SJ, DeGirolami U, et al. Thresholds of focal cerebral ischemia in awake monkeys. J Neurosurg. 1981; 54(6):773-82. [PubMed: 7241187]

3. Ostrowski RP, Colohan AR, Zhang JH. Molecular mechanisms of early brain injury after subarachnoid hemorrhage. Neurol Res. 2006; 28(4):399-414. [PubMed: 16759443]

4. Jean WC, Spellman SR, Nussbaum ES, Low WC. Reperfusion injury after focal cerebral ischemia: the role of inflammation and the therapeutic horizon. Neurosurgery. 1998; 43(6):1382-96. [PubMed: 9848853]

5. Siesjo BK, Agardh CD, Bengtsson F. Free radicals and brain damage. Cerebrovasc Brain Metab Rev. 1989; 1(3):165-211. [PubMed: 2701375]

6. Hademenos GJ, Massoud TF. Biophysical mechanisms of stroke. Stroke. 1997; 28(10):2067-77. [PubMed: 9341720]

7. Garcia JH, Liu KF, Yoshida Y, Lian J, Chen S, del Zoppo GJ. Influx of leukocytes and platelets in an evolving brain infarct (Wistar rat). Am J Pathol. 1994; 144(1):188-99. [PubMed: 8291608]

8. Siesjo BK. Cell damage in the brain: a speculative synthesis. J Cereb Blood Flow Metab. 1981; 1(2):155-85. [PubMed: 6276420]

9. Becker KJ. Inflammation and acute stroke. Curr Opin Neurol. 1998; 11(1):45-9. [PubMed: 9484616]

10. Cuzzocrea S, Riley DP, Caputi AP, Salvemini D. Antioxidant therapy: a new pharmacological approach in shock, inflammation, and ischemia/reperfusion injury. Pharmacol Rev. 2001; 53(1): 135-59. [PubMed: 11171943]

11. Valko M, Leibfritz D, Moncol J, Cronin MT, Mazur M, Telser J. Free radicals and antioxidants in normal physiological functions and human disease. Int J Biochem Cell Biol. 2007; 39(1):44-84. [PubMed: 16978905]

12. Janardhan V, Qureshi AI. Mechanisms of ischemic brain injury. Curr Cardiol Rep. 2004; 6(2):11723. [PubMed: 14759356]

13. Haddad JJ. Redox regulation of pro-inflammatory cytokines and IkappaB-alpha/NF-kappaB nuclear translocation and activation. Biochem Biophys Res Commun. 2002; 296(4):847-56. [PubMed: 12200125]

14. Cao W, Carney JM, Duchon A, Floyd RA, Chevion M. Oxygen free radical involvement in ischemia and reperfusion injury to brain. Neurosci Lett. 1988; 88(2):233-8. [PubMed: 3380359]

15. Juurlink BH, Sweeney MI. Mechanisms that result in damage during and following cerebral ischemia. Neurosci Biobehav Rev. 1997; 21(2):121-8. [PubMed: 9062934]

16. Wagner KR, Jauch EC. Extending the window for acute stroke treatment: thrombolytics plus CNS protective therapies. Exp Neurol. 2004; 188(2):195-9. [PubMed: 15246819]

17. Fisher M. The ischemic penumbra: identification, evolution and treatment concepts. Cerebrovasc Dis. 2004; 17 (Suppl 1):1-6. [PubMed: 14694275]

18. Turner R, Vink R. Inhibition of neurogenic inflammation as a novel treatment for ischemic stroke. Timely Top Med Cardiovasc Dis. 2007; 11:E24. [PubMed: 18297137]

19. Bambauer KZ, Johnston SC, Bambauer DE, Zivin JA. Reasons why few patients with acute stroke receive tissue plasminogen activator. Arch Neurol. 2006; 63(5):661-4. [PubMed: 16682535]

20. Su EJ, Fredriksson L, Geyer M, Folestad E, Cale J, Andrae J, et al. Activation of PDGF-CC by tissue plasminogen activator impairs blood-brain barrier integrity during ischemic stroke. Nat Med. 2008; 14(7):731-7. [PubMed: 18568034]

21. Yepes M, Sandkvist M, Moore EG, Bugge TH, Strickland DK, Lawrence DA. Tissue-type plasminogen activator induces opening of the blood-brain barrier via the LDL receptor-related protein. J Clin Invest. 2003; 112(10):1533-40. [PubMed: 14617754]

22. Goto H, Fujisawa H, Oka F, Nomura S, Kajiwara K, Kato S, et al. Neurotoxic effects of exogenous recombinant tissue-type plasminogen activator on the normal rat brain. J Neurotrauma. 2007; 24(4):745-52. [PubMed: 17439356] 
23. Zaidat OO, Suarez JI, Santillan C, Sunshine JL, Tarr RW, Paras VH, et al. Response to intraarterial and combined intravenous and intra-arterial thrombolytic therapy in patients with distal internal carotid artery occlusion. Stroke. 2002; 33(7):1821-6. [PubMed: 12105360]

24. Rha JH, Saver JL. The impact of recanalization on ischemic stroke outcome: a meta-analysis. Stroke. 2007; 38(3):967-73. [PubMed: 17272772]

25. Nogueira RG, Yoo AJ, Buonanno FS, Hirsch JA. Endovascular approaches to acute stroke, part 2: a comprehensive review of studies and trials. AJNR. 2009; 30(5):859-75. [PubMed: 19386727]

26. Lewandowski CA, Frankel M, Tomsick TA, Broderick J, Frey J, Clark W, et al. Combined intravenous and intra-arterial r-TPA versus intra-arterial therapy of acute ischemic stroke: Emergency Management of Stroke (EMS) Bridging Trial. Stroke. 1999; 30(12):2598-605. [PubMed: 10582984]

27. The Interventional Management of Stroke (IMS) II Study. Stroke. 2007; 38(7):2127-35. [PubMed: 17525387]

28. Smith WS. Safety of mechanical thrombectomy and intravenous tissue plasminogen activator in acute ischemic stroke. Results of the multi Mechanical Embolus Removal in Cerebral Ischemia (MERCI) trial, part I. AJNR. 2006; 27(6):1177-82. [PubMed: 16775259]

29. Smith WS, Sung G, Saver J, Budzik R, Duckwiler G, Liebeskind DS, et al. Mechanical thrombectomy for acute ischemic stroke: final results of the Multi MERCI trial. Stroke. 2008; 39(4):1205-12. [PubMed: 18309168]

30. Brekenfeld C, Schroth G, El-Koussy M, Nedeltchev K, Reinert M, Slotboom J, et al. Mechanical thromboembolectomy for acute ischemic stroke: comparison of the catch thrombectomy device and the Merci Retriever in vivo. Stroke. 2008; 39(4):1213-9. [PubMed: 18309173]

31. Liebig T, Reinartz J, Hannes R, Miloslavski E, Henkes H. Comparative in vitro study of five mechanical embolectomy systems: effectiveness of clot removal and risk of distal embolization. Neuroradiology. 2008; 50(1):43-52. [PubMed: 17932666]

32. Natarajan SK, Snyder KV, Siddiqui AH, Ionita CC, Hopkins LN, Levy EI. Safety and effectiveness of endovascular therapy after 8 hours of acute ischemic stroke onset and wakeup strokes. Stroke. 2009; 40(10):3269-74. [PubMed: 19628808]

33. The penumbra pivotal stroke trial: safety and effectiveness of a new generation of mechanical devices for clot removal in intracranial large vessel occlusive disease. Stroke. 2009; 40(8):2761-8. [PubMed: 19590057]

34. Struffert T, Kohrmann M, Engelhorn T, Nowe T, Richter G, Schellinger PD, et al. Penumbra Stroke System as an "add-on" for the treatment of large vessel occlusive disease following thrombolysis: first results. European radiology. 2009; 19(9):2286-93. [PubMed: 19350248]

35. Nogueira RG, Schwamm LH, Hirsch JA. Endovascular approaches to acute stroke, part 1: Drugs, devices, and data. AJNR. 2009; 30(4):649-61. [PubMed: 19279271]

36. Abou-Chebl A, Bajzer CT, Krieger DW, Furlan AJ, Yadav JS. Multimodal therapy for the treatment of severe ischemic stroke combining GPIIb/IIIa antagonists and angioplasty after failure of thrombolysis. Stroke. 2005; 36(10):2286-8. [PubMed: 16179581]

37. Levy EI, Siddiqui AH, Crumlish A, Snyder KV, Hauck EF, Fiorella DJ, et al. First Food and Drug Administration-approved prospective trial of primary intracranial stenting for acute stroke: SARIS (stent-assisted recanalization in acute ischemic stroke). Stroke. 2009; 40(11):3552-6. [PubMed: 19696415]

38. Jahan R. Solitaire flow-restoration device for treatment of acute ischemic stroke: safety and recanalization efficacy study in a swine vessel occlusion model. AJNR. 2010; 31(10):1938-43. [PubMed: 20634306]

39. Hofmeijer J, Schepers J, Veldhuis WB, Nicolay K, Kappelle LJ, Bar PR, et al. Delayed decompressive surgery increases apparent diffusion coefficient and improves peri-infarct perfusion in rats with space-occupying cerebral infarction. Stroke. 2004; 35(6):1476-81. [PubMed: 15131314]

40. Hacke W, Schwab S, Horn M, Spranger M, De Georgia M, von Kummer R. 'Malignant' middle cerebral artery territory infarction: clinical course and prognostic signs. Archives of neurology. 1996; 53(4):309-15. [PubMed: 8929152] 
41. Adams HP Jr, del Zoppo G, Alberts MJ, Bhatt DL, Brass L, Furlan A, et al. Guidelines for the early management of adults with ischemic stroke: a guideline from the American Heart Association/American Stroke Association Stroke Council, Clinical Cardiology Council, Cardiovascular Radiology and Intervention Council, and the Atherosclerotic Peripheral Vascular Disease and Quality of Care Outcomes in Research Interdisciplinary Working Groups: the American Academy of Neurology affirms the value of this guideline as an educational tool for neurologists. Stroke. 2007; 38(5):1655-711. [PubMed: 17431204]

42. Schwab S, Steiner T, Aschoff A, Schwarz S, Steiner HH, Jansen O, et al. Early hemicraniectomy in patients with complete middle cerebral artery infarction. Stroke. 1998; 29(9):1888-93. [PubMed: 9731614]

43. Adibhatla RM, Hatcher JF. Altered lipid metabolism in brain injury and disorders. Subcell Biochem. 2008; 49:241-68. [PubMed: 18751914]

44. Adibhatla RM, Hatcher JF. Tissue plasminogen activator (tPA) and matrix metalloproteinases in the pathogenesis of stroke: therapeutic strategies. CNS Neurol Disord Drug Targets. 2008; 7(3): 243-53. [PubMed: 18673209]

45. Margaill I, Plotkine M, Lerouet D. Antioxidant strategies in the treatment of stroke. Free Radic Biol Med. 2005; 39(4):429-43. [PubMed: 16043015]

46. Francis JW, Ren J, Warren L, Brown RH Jr, Finklestein SP. Postischemic infusion of Cu/Zn superoxide dismutase or SOD:Tet451 reduces cerebral infarction following focal ischemia/ reperfusion in rats. Exp Neurol. 1997; 146(2):435-43. [PubMed: 9270054]

47. Schaller B, Graf R. Cerebral ischemia and reperfusion: the pathophysiologic concept as a basis for clinical therapy. J Cereb Blood Flow Metab. 2004; 24(4):351-71. [PubMed: 15087705]

48. Forsman M, Fleischer JE, Milde JH, Steen PA, Michenfelder JD. Superoxide dismutase and catalase failed to improve neurologic outcome after complete cerebral ischemia in the dog. Acta Anaesthesiol Scand. 1988; 32(2):152-5. [PubMed: 3348076]

49. Schurer L, Grogaard B, Gerdin B, Arfors KE. Superoxide dismutase does not prevent delayed hypoperfusion after incomplete cerebral ischaemia in the rat. Acta Neurochir (Wien). 1990; 103(3-4):163-70. [PubMed: 2399844]

50. Tsubokawa T, Jadhav V, Solaroglu I, Shiokawa Y, Konishi Y, Zhang JH. Lecithinized superoxide dismutase improves outcomes and attenuates focal cerebral ischemic injury via antiapoptotic mechanisms in rats. Stroke. 2007; 38(3):1057-62. [PubMed: 17272760]

51. Kim DW, Eum WS, Jang SH, Kim SY, Choi HS, Choi SH, et al. Transduced Tat-SOD fusion protein protects against ischemic brain injury. Mol Cells. 2005; 19(1):88-96. [PubMed: 15750345]

52. Veronese FM, Caliceti P, Schiavon O, Sergi M. Polyethylene glycol-superoxide dismutase, a conjugate in search of exploitation. Adv Drug Deliv Rev. 2002; 54(4):587-606. [PubMed: 12052716]

53. Morris MC, Depollier J, Mery J, Heitz F, Divita G. A peptide carrier for the delivery of biologically active proteins into mammalian cells. Nat Biotechnol. 2001; 19(12):1173-6. [PubMed: 11731788]

54. Imaizumi S, Woolworth V, Fishman RA, Chan PH. Liposome-entrapped superoxide dismutase reduces cerebral infarction in cerebral ischemia in rats. Stroke. 1990; 21(9):1312-7. [PubMed: 2396268]

55. Sinha J, Das N, Basu MK. Liposomal antioxidants in combating ischemia-reperfusion injury in rat brain. Biomed Pharmacother. 2001; 55(5):264-71. [PubMed: 11428552]

56. Reddy MK, Wu L, Kou W, Ghorpade A, Labhasetwar V. Superoxide Dismutase-Loaded PLGA Nanoparticles Protect Cultured Human Neurons Under Oxidative Stress. Appl Biochem Biotechnol. 2008; 151(2-3):565-77. [PubMed: 18509606]

57. Reddy MK, Labhasetwar V. Nanoparticle-mediated delivery of superoxide dismutase to the brain: an effective strategy to reduce ischemia-reperfusion injury. FASEB J. 2009; 23(5):1384-95. [PubMed: 19124559]

58. Rosenberg GA, Yang Y. Vasogenic edema due to tight junction disruption by matrix metalloproteinases in cerebral ischemia. Neurosurg Focus. 2007; 22(5):E4. [PubMed: 17613235]

59. Kuroda S, Siesjo BK. Reperfusion damage following focal ischemia: pathophysiology and therapeutic windows. Clin Neurosci. 1997; 4(4):199-212. [PubMed: 9186042] 
60. Yasui K, Baba A. Therapeutic potential of superoxide dismutase (SOD) for resolution of inflammation. Inflammation Res. 2006; 55(9):359-63.

61. Zhang Z, Zhang RL, Jiang Q, Raman SB, Cantwell L, Chopp M. A new rat model of thrombotic focal cerebral ischemia. J Cereb Blood Flow Metab. 1997; 17(2):123-35. [PubMed: 9040491]

62. Habeck M. New stroke therapies -- hope for the future. Drug Discov Today. 2002; 7(3):157-9. [PubMed: 11815225]

63. Green AR, Shuaib A. Therapeutic strategies for the treatment of stroke. Drug Discov Today. 2006; 11(15-16):681-93. [PubMed: 16846795]

64. Guyot LL, Diaz FG, O’Regan MH, McLeod S, Park H, Phillis JW. Real-time measurement of glutamate release from the ischemic penumbra of the rat cerebral cortex using a focal middle cerebral artery occlusion model. Neurosci Lett. 2001; 299(1-2):37-40. [PubMed: 11166932]

65. Boast CA, Gerhardt SC, Pastor G, Lehmann J, Etienne PE, Liebman JM. The N-methyl-Daspartate antagonists CGS 19755 and CPP reduce ischemic brain damage in gerbils. Brain Res. 1988; 442(2):345-8. [PubMed: 3285958]

66. Gotti B, Duverger D, Bertin J, Carter C, Dupont R, Frost J, et al. Ifenprodil and SL 82.0715 as cerebral anti-ischemic agents. I. Evidence for efficacy in models of focal cerebral ischemia. J Pharmacol Exp Ther. 1988; 247(3):1211-21. [PubMed: 2849668]

67. Aronowski J, Ostrow P, Samways E, Strong R, Zivin JA, Grotta JC. Graded bioassay for demonstration of brain rescue from experimental acute ischemia in rats. Stroke. 1994; 25(11): 2235-40. [PubMed: 7526488]

68. Horn J, Limburg M. Calcium antagonists for acute ischemic stroke. Cochrane Database Syst Rev. 2000; (2):CD001928. [PubMed: 10796454]

69. Noh SJ, Lee JM, Lee KS, Hong HS, Lee CK, Cho IH, et al. SP-8203 shows neuroprotective effects and improves cognitive impairment in ischemic brain injury through NMDA receptor. Pharmacol Biochem Behav. 100(1):73-80. [PubMed: 21835192]

70. Leker RR, Shohami E. Cerebral ischemia and trauma-different etiologies yet similar mechanisms: neuroprotective opportunities. Brain Res Brain Res Rev. 2002; 39(1):55-73. [PubMed: 12086708]

71. Feuerstein GZ, Zaleska MM, Krams M, Wang X, Day M, Rutkowski JL, et al. Missing steps in the STAIR case: a Translational Medicine perspective on the development of NXY-059 for treatment of acute ischemic stroke. J Cereb Blood Flow Metab. 2008; 28(1):217-9. [PubMed: 17579658]

72. Saver JL, Kidwell C, Eckstein M, Starkman S. Prehospital neuroprotective therapy for acute stroke: results of the Field Administration of Stroke Therapy-Magnesium (FAST-MAG) pilot trial. Stroke. 2004; 35(5):e106-8. [PubMed: 15017009]

73. Albers GW, Goldstein LB, Hess DC, Wechsler LR, Furie KL, Gorelick PB, et al. Stroke Treatment Academic Industry Roundtable (STAIR) recommendations for maximizing the use of intravenous thrombolytics and expanding treatment options with intra-arterial and neuroprotective therapies. Stroke. 2011; 42(9):2645-50. [PubMed: 21852620]

74. Deb P, Sharma S, Hassan KM. Pathophysiologic mechanisms of acute ischemic stroke: An overview with emphasis on therapeutic significance beyond thrombolysis. Pathophysiology. 17(3): 197-218. [PubMed: 20074922]

75. Gedikli O, Baykan M. Statins in stroke prevention. Anadolu Kardiyol Derg. 2008; 8(3):217-22. [PubMed: 18524729]

76. Cheng YD, Al-Khoury L, Zivin JA. Neuroprotection for ischemic stroke: two decades of success and failure. NeuroRx. 2004; 1(1):36-45. [PubMed: 15717006]

77. Shintani Y, Terao Y, Ohta H. Molecular Mechanisms Underlying Hypothermia-Induced Neuroprotection. Stroke Research and Treatment. 2011; 2011

78. Lundbye JB, Rai M, Ramu B, Hosseini-Khalili A, Li D, Slim HB, et al. Therapeutic hypothermia is associated with improved neurologic outcome and survival in cardiac arrest survivors of nonshockable rhythms. Resuscitation. 2011

79. Jacobs SE, Morley CJ, Inder TE, Stewart MJ, Smith KR, McNamara PJ, et al. Whole-body hypothermia for term and near-term newborns with hypoxic-ischemic encephalopathy: a randomized controlled trial. Arch Pediatr Adolesc Med. 2011; 165(8):692-700. [PubMed: 21464374] 
80. Hemmen TM, Raman R, Guluma KZ, Meyer BC, Gomes JA, Cruz-Flores S, et al. Intravenous thrombolysis plus hypothermia for acute treatment of ischemic stroke (ICTuS-L): final results. Stroke. 2010; 41(10):2265-70. [PubMed: 20724711]

81. Ohta K, Graf R, Rosner G, Heiss WD. Calcium ion transients in peri-infarct depolarizations may deteriorate ion homeostasis and expand infarction in focal cerebral ischemia in cats. Stroke. 2001; 32(2):535-43. [PubMed: 11157194]

82. Gribkoff VK, Starrett JE Jr, Dworetzky SI, Hewawasam P, Boissard CG, Cook DA, et al. Targeting acute ischemic stroke with a calcium-sensitive opener of maxi-K potassium channels. Nat Med. 2001; 7(4):471-7. [PubMed: 11283675]

83. Cheng Y, Deshmukh M, D'Costa A, Demaro JA, Gidday JM, Shah A, et al. Caspase inhibitor affords neuroprotection with delayed administration in a rat model of neonatal hypoxic-ischemic brain injury. J Clin Invest. 1998; 101(9):1992-9. [PubMed: 9576764]

84. Endres M, Namura S, Shimizu-Sasamata M, Waeber C, Zhang L, Gomez-Isla T, et al. Attenuation of delayed neuronal death after mild focal ischemia in mice by inhibition of the caspase family. $\mathrm{J}$ Cereb Blood Flow Metab. 1998; 18(3):238-47. [PubMed: 9498840]

85. Ehrenreich H, Weissenborn K, Prange H, Schneider D, Weimar C, Wartenberg K, et al. Recombinant human erythropoietin in the treatment of acute ischemic stroke. Stroke. 2009; 40(12):e647-56. [PubMed: 19834012]

86. Wiltrout C, Lang B, Yan Y, Dempsey RJ, Vemuganti R. Repairing brain after stroke: a review on post-ischemic neurogenesis. Neurochem Int. 2007; 50(7-8):1028-41. [PubMed: 17531349]

87. Kennea NL, Mehmet H. Neural stem cells. J Pathol. 2002; 197(4):536-50. [PubMed: 12115869]

88. Roitberg B. Transplantation for stroke. Neurol Res. 2004; 26(3):256-64. [PubMed: 15142317]

Drug Deliv Transl Res. Author manuscript; available in PMC 2012 December 1. 


\section{Summary}

The main challenge in stroke therapy is how to rescue patients who have survived the ischemic insult, considering that by the time they are evaluated, the majority might have passed the 3-h window in which to receive t-PA therapy. Therefore, the prime issues are: i) how to extend the window of treatment; ii) how to minimize the effect of reperfusion injury, considering that the damaging effect due to reperfusion sometimes could be greater than that due to ischemia itself; iii) how to reduce the risks associated with t-PA therapy beyond $3 \mathrm{~h}$; and iv) how to regenerate infarcted brain areas to regain neurological function. New advances that combine the basic understanding of pathobiology of the disease and translational research including drug delivery approaches and surgical interventions could address the complex issues associated with stroke therapy. 


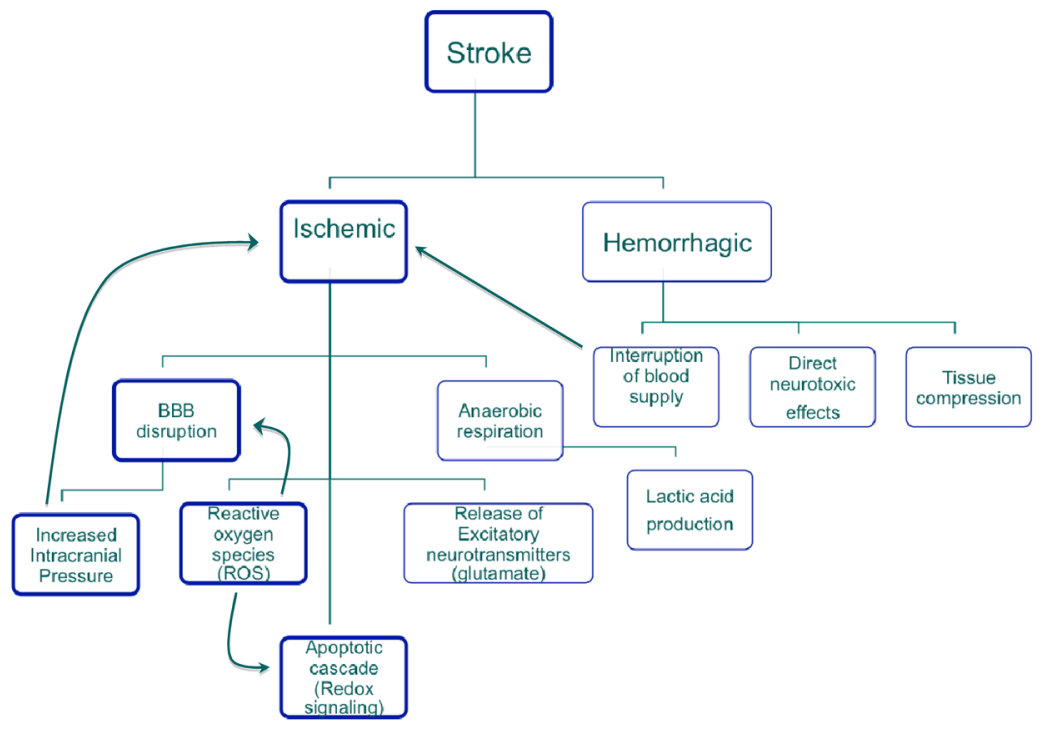

Figure 1.

Schematic showing different types of stroke and cascade of events following ischemia. 
A

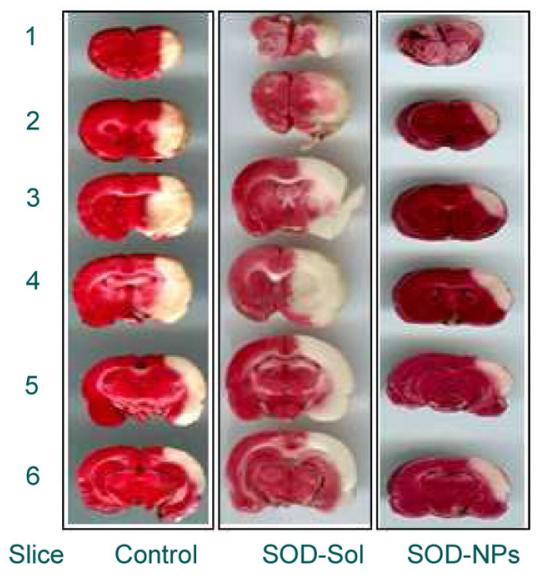

B

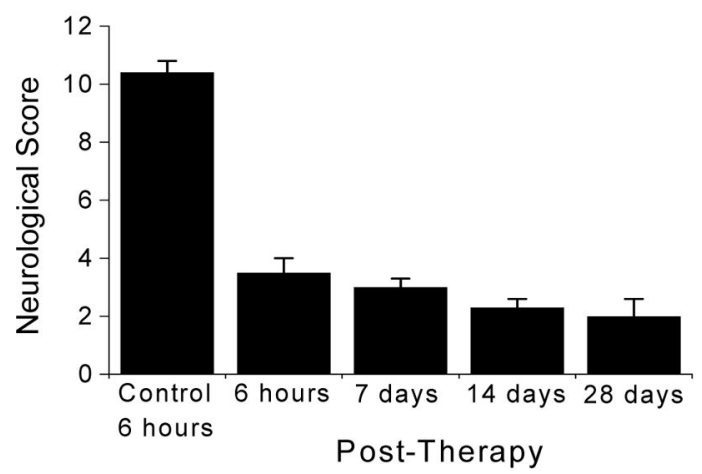

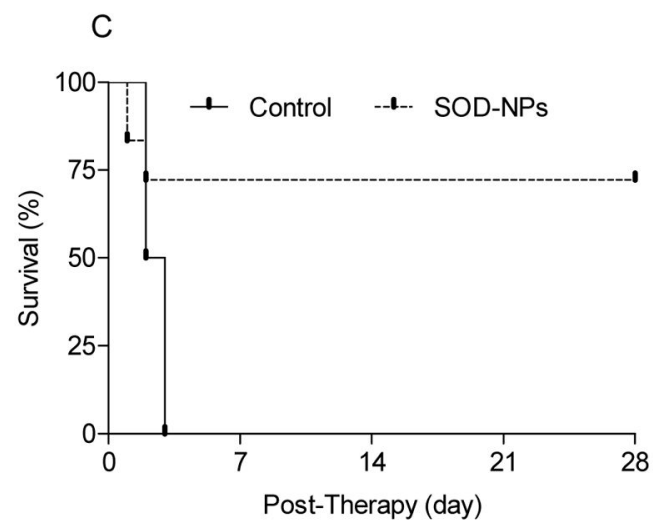

Figure 2.

Efficacy of SOD-NPs in rat stroke model. Transient focal cerebral ischemia was accomplished by middle cerebral artery occlusion using a suture in rats. One hour after ischemia, a suspension of SOD-NPs was infused through the carotid artery at the time of reperfusion. In acute studies, animals were evaluated for neurological parameters prior to euthanization at $6 \mathrm{hrs}$ following reperfusion; brain were harvested to measure infract volume. In chronic studies, the same protocol was followed but animals were allowed to recover. Different controls were used including control NPs, SOD in solution, control NPs mixed with SOD in solution. SOD-NPs reduce infarcted area, improve neurological scores, and increase survival in rat middle cerebral artery occlusion ischemic stroke model. A) Representative coronal brain sections stained with 2,3,5-triphenyltetrazolium chloride (TTC) solution from animals treated with saline control, SOD-Sol, or SOD-NPs. Dark colored regions in the TTC-stained sections indicate nonischemic areas; pale-colored regions indicate ischemic portions of the brain. B) Bar graph showing neurological severity score. Lower scores represent better neurological recovery. Control is saline control at $6 \mathrm{~h}$ following reperfusion. Data are shown as means \pm SE. C) Survival of animals treated with SOD-NPs compared with saline control. All animals treated with saline only died within $3 \mathrm{~d}$, whereas more than $75 \%$ of the animals treated with SOD-NPs not only survived but showed improvement in neurological recovery with time ( $* P=0.06$ at $28 \mathrm{~d}$ compared to $6 \mathrm{~h}$ ). Figure reproduced with permission from Ref [57]. 
A

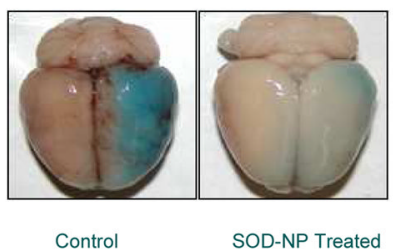

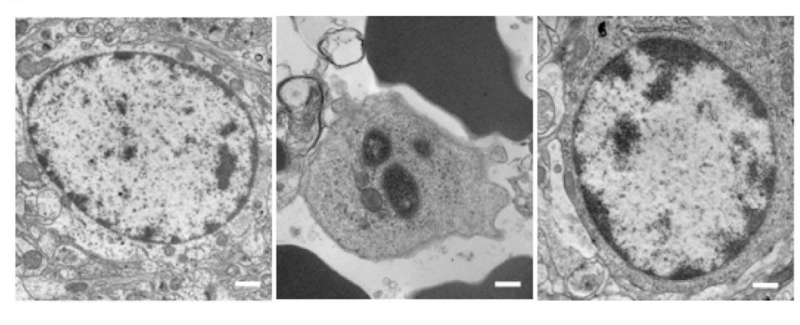

Sham Control

Untreated

SOD-NP Treated

Figure 3.

Mechanism of neuroprotection treated with SOD-NPs. Animal from the acute study were analyzed for BBB integrity and histological analysis. A) Representative brain showing Evans blue leakage in saline control and SOD-NPs-treated rats at $6 \mathrm{~h}$ after reperfusion. More blue color represents breakdown of BBB. B) Representative electron microscopic photomicrographs of penumbral region of brain sections of sham, saline control, and SODNPs-treated rats at $6 \mathrm{~h}$ after reperfusion. The results show inhibition of apoptosis in SODNPs-treated animals whereas saline control shows apoptotic nucleus. Bar $=500 \mathrm{~nm}$. Figure reproduced with permission from Ref [57]. 